\title{
The effect of mine induced tremors on seismic response of soil-steel bridges
}

\author{
Tomasz Maleska, and Damian Beben* \\ Opole University of Technology, Faculty of Civil Engineering and Architecture, 45-061 Opole, \\ Katowicka 48, Poland
}

\begin{abstract}
Rockburst are similar phenomena like low intensity natural earthquake. They can be observed in Upper and Lower Silesia regions. Analyses of soil-steel bridges under seismic excitation are so far limited. The rockburst is related to the mining exploitation. The influence of rockburst on the soil-steel bridges should be investigated, because this ground motions differ with many respects from natural earthquakes. The span of soil-steel bridges is typically range from 3 to $25 \mathrm{~m}$, so they can be used as an effectives alternative for a short-span bridges. The soil-steel bridges can meet the design and safety requirements similar to traditional bridges, at lower costs. For these reasons, soil-steel bridges are more frequently used in road and railway projects in many parts of the World. This paper presents results of numerical study of soil-steel bridge under rockburst induced ground excitations. Response characteristic axial of the soil-steel bridge caused by rockburts are analysed in detail. The obtained results are compared with the ones computed under El Centro using the seismic benchmark record.
\end{abstract}

\section{Introduction}

Soil-steel bridges have become quite popular in recent years particularly in Europe, USA and Canada. The greatest advantages of this type of structures are: (i) low construction costs, (ii) minimum steel usage in comparison with traditional bridges, (ii) the speed of construction, (iv) the possibility of prefabrication of the steel shell [1]. Moreover, these bridges can be built within in the framework of sustainable development ideas. Despite the numerous advantages, these structures have also drawbacks such as limited span which rarely exceeds 25 meters [2]. Also the issue of durability of these bridges remain to be understood [3].

Paraseismic excitation from rockburst are similar to shallow and weak natural earthquakes. In Poland some rockburst reached 4.5 magnitude on the Richter scale and their maximum surface intensities exceeded VI on Mercalli scale. In the other parts of the world mining rockbursts reached even 5.5 magnitude [4].

Over the last few years several publications have been written. They analysed the influence and effects of mining rockbursts on building structures. For instance Zembaty and Kokot [5] presented the a methodology of designing civil engineering structures under rockbursts excitation. For these purposes of Eurocode 8 was adopted for designing new

\footnotetext{
*Corresponding author:d.beben@po.opole.pl
} 
structures. Rational approach was applied to determine the values of seismic design forces by the use of maximum horizontal ground velocity as a measure of mining rockburst intensity. In the same way the paraseismic phenomena were defined in the paper written by Zembaty [6] where 18 low intensity seismic records were applied using response spectrum method. In addition, Bonkowski et al. [7] analysed leaning structures loaded. To solve the problem the program SAP2000 was applied which uses the Finite Element Method (FEM). Moreover, the Time History method was used for data analysis.

The problem of seismic response of bridges is well represented in the Literature, however with very few examples of the culverts. For example, Sawamura et al. [8] applied the Time History analysis to analyse the impact of seismic excitations on arch reinforced concrete (RC) culverts. In case of the analysis of soil-steel culverts and bridges in terms of the evaluation of seismic loads impact, the World Literature is rather poor. There are merely a few papers on this subject. For example Abuhajar et al. [9] analysed the impact of seismic excitations on box-shaped steel culverts. For this purpose scale models were used in experimental studies. To evaluate the impact of earthquake on culverts three different seismic excitations records were used. Mahgoub \& El Naggar [10] analysed the seismic excitations impact on soil-steel bridges, and they results were compared with the Canadian code [11]. In the analyses they used three records of earthquakes with different intensity and duration. It was found that compatibility of their numerical analyses with the Canadian code were confirmed only in cases of short tremors with high values of ground accelerations. Their analysis was performed using FLAC software and respective numerical model made as 2D.

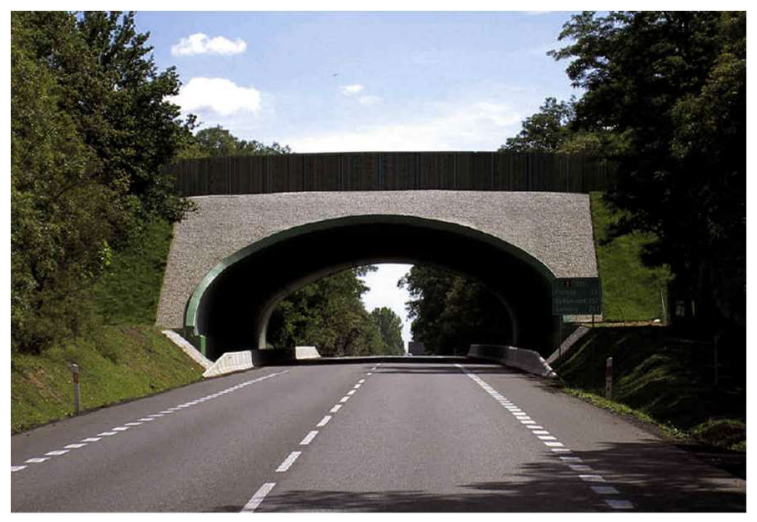

Fig. 1. Side view on analysed soil-steel bridge.

In contrast, Maleska et al. [12] concentrated on the numerical analysis of soil-steel bridge with various directions of seismic load. Maximum values of stresses in steel shell were achieved when loads were applied perpendicularly to the bridge. In addition, they analysed the influence of contact soil-steel zone during seismic excitations. Davis and Bardet [13] analysed the impact of seismic excitations on soil-steel culvert. However, in this case, they analysed on steel pipes buried in the ground which survived an earthquake.

The main purpose of the paper is to present results the effect of rockburst induced and seismic excitations on a soil-steel bridge. The problem is important due to the fact that soilsteel bridges are often in the mine exploitation areas. The seismic response of selected bridge was analysed using two records of rockbursts with different intensity and duration. Additionally the results were compared with El Centro benchmark excitation. This is important because natural earthquake differ from rockburst with respect to this intensity, duration and spectral characteristic. 


\section{A description of analysed model}

\subsection{A brief description of a bridge}

In order to analyse the impact of mining rockbursts on a soil-steel bridge, a real object built in Poland (Fig. 1) was used as a passage for animals. The bridge has the following parameters: span $-17.67 \mathrm{~m}$, clear height $-6.05 \mathrm{~m}$, thickness of corrugated steel plate $-0.007 \mathrm{~m}$, corrugation depth $-0.14 \mathrm{~m}$, corrugation pitch $-0.38 \mathrm{~m}$, the length of the bridge in a crown $40.39 \mathrm{~m}$, the length of the bridge at the base of foundation $-53.83 \mathrm{~m}$. To connect the steel corrugated plate sheets, the screws with $\varnothing=20 \mathrm{~mm}$ were used with a $350-400 \mathrm{Nm}$ torque value.

The support for steel shell is formed by RC continuous footing with the length of 53.83 $\mathrm{m}$ and width of $4.0 \mathrm{~m}$ made of $\mathrm{C} 25 / 30$ concrete. The backfill was made of $0.2-0.3$ thick layers of 10-32 diameter aggregate. In order to maintain a proper interaction of shell with soil, the backfill was compacted to reach $I_{D}=95 \%$ on Proctor scale. The height of backfill in the shell crown is $1.80 \mathrm{~m}$. Such thickness of the backfill ensures proper dumping caused by traffic and gives also the possibility of planting various vegetation. It is extremely important due to environmental nature of the object.

\subsection{The description of numerical model}

The numerical program DIANA FEA [14] based on FEM was used to analyse the impact of mining rockbursts on a selected soil-steel bridge. The similar assumptions as in Maleska et al. [12] were used in the numerical modelling of the bridge. The following material characteristics were used for the analysis:

- corrugated steel plate was modelled as shell curved elements (Q24IF), Young modulus of $205 \mathrm{GPa}$, Poisson ratio 0.3 , elastic-plastic model with density of $7850 \mathrm{~kg} / \mathrm{m}^{2}$, the yield strength of steel of $235 \mathrm{MPa}$, moment of inertia of $21897.45 \mathrm{~mm} / \mathrm{mm}$, cross section area of $8.867 \mathrm{~mm}^{2} / \mathrm{mm}$, and plate thickness of $0.007 \mathrm{~m}$,

- backfill with height of $1.8 \mathrm{~m}$ was modelled as solid elements (HX24L) with DuncanChang nonlinear elastic hyperbolic model. The following backfill parameters were applied: Young modulus of $100 \mathrm{MPa}$, material density of $2050 \mathrm{~kg} / \mathrm{m}^{2}$, Poisson ratio of 0.2 , dilation angle of $5^{\circ}$, angle of internal friction of $39^{\circ}$, cohesion of $3000 \mathrm{~N}$, failure ratio $R_{f}=0.7$, unloading-reloading stiffness $E_{u \mathrm{r}}=1000 \mathrm{~N} / \mathrm{m}^{2}$, reference pressure $P_{\text {ref }}=101350 \mathrm{~N} / \mathrm{m}^{2}$, exponent for unloading reloading curve $m=0.25$, exponent for backbone curve $n=1.1$, minimum compressive stress $350 \mathrm{~N} / \mathrm{m}^{2}$, and minimum tangential stiffness of backbone curve $E_{t, \min }=1200 \mathrm{~N} / \mathrm{m}^{3}$,

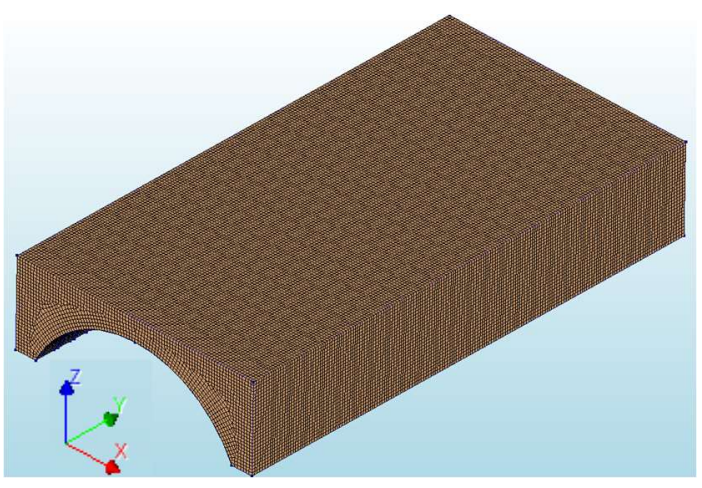

Fig. 2. Numerical model of soil-steel bridge in DIANA program. 
- boundary conditions were modelled as non-transferable support of the shell walls and on all boundary walls of the soil for $\mathrm{x}, \mathrm{y}, \mathrm{z}$ directions,

- connection between backfill and steel was modelled as automatic interface by applied function "Coulomb friction" with angle of internal friction of $39^{\circ}$, dilation angle of $5^{\circ}$, rigidity of $100000 \mathrm{kN} / \mathrm{m}^{3}$, and cohesion of $3000 \mathrm{~N}$,

- the finite elements were modelled as quadratic elements with dimensions of $0.25 \times 0.25$ $\mathrm{m}$ for backfill and corrugated steel shell (Fig. 2).

The corrugated shell was modelled as flat with the use of orthotropic characteristics (Fig. 3). Such an approach allows to simplify the shell modelling as well as shortens calculation time without obtaining increased external forces values [15].
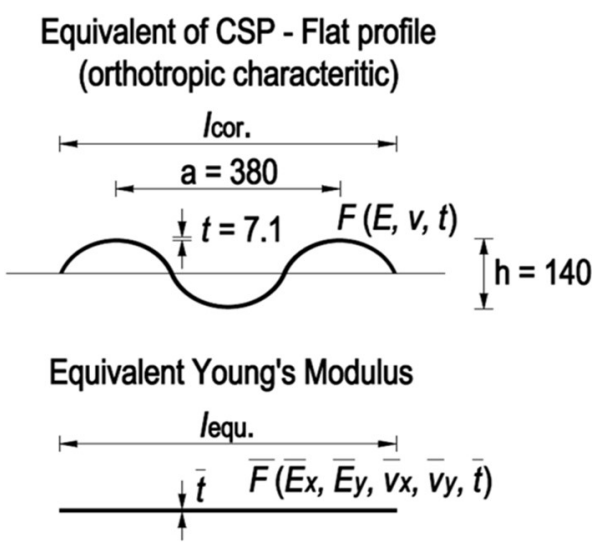

Fig. 3. Characteristics of orthotropic steel shell used for numerical modelling.

The transformation of corrugated shell to a flat one was conducted according to the procedure presented in the paper $[15,16]$, according to which the difference in results does not exceed $2-5 \%$. The orthotropic shell can be defined into a flat one using the following correlation:

- equivalent thickness of plate:

$$
t_{e q u}=\sqrt{12\left(1-v^{2}\right) \frac{I}{A}},
$$

where $I$ is moment of inertia, $A$ is cross-sectional area, $v$ is Poisson ratio,

- equivalent elastic modulus of material (Young modulus) in circumferential direction of shell:

$$
E_{x, e q u}=E \frac{A}{a t_{e q u .}},
$$

where $a$ is a pitch of corrugation, $E$ is a Young modulus,

- equivalent elastic shear modulus:

$$
E_{y, \text { equ }}=E\left(\frac{t}{t_{\text {equ. }}}\right)^{3},
$$

- equivalent Poisson ratio:

$$
v_{e q u}=v \frac{E_{y, e q u} .}{E_{x, e q u .} .}
$$




\section{The results of a seismic analysis}

The paper involved the numerical analysis of a soil-steel bridge with the use of Time History method. To conduct the seismic analysis, two records of mining rockbursts were used: from Upper Silesian Coal Basin from 12 Dec 2015 (Fig. 4a) and from 14 Dec 2015 (Fig. 4b). The first record of the tremor is greater and lasts 8.63 seconds, while the other is a little shorter and lasts 7.615 seconds. The maximum ground accelerations were $0.8 \mathrm{~m} / \mathrm{s}^{2}$ and $0.438 \mathrm{~m} / \mathrm{s}^{2}$ for the rockburst from $12 \mathrm{Dec} 2015$ and $14 \mathrm{Dec} 2015$, respectively. The difference in ground accelerations between two rockbursts is $45.3 \%$. The magnitude for the stronger tremor from 12 Dec 2015 is about 2.5 on Richter scale.

a)

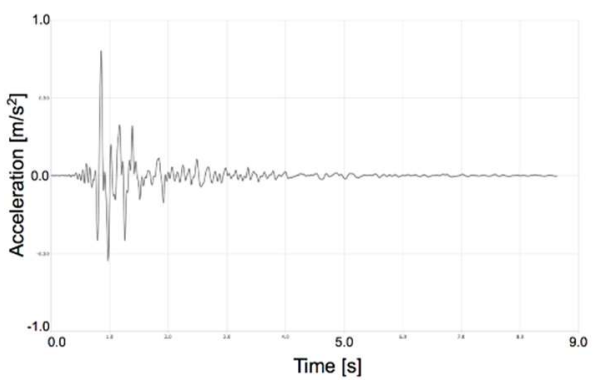

b)

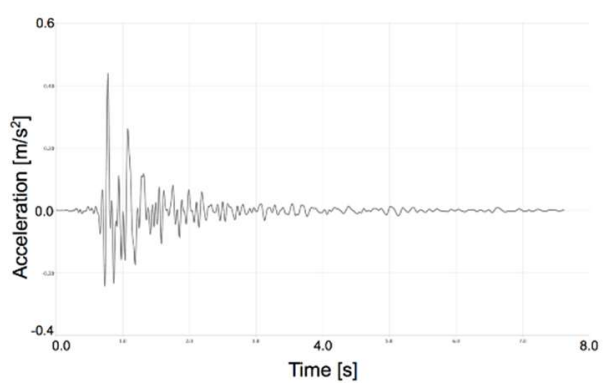

Fig. 4. Records of mining rockbursts from: a) 12 Dec 2015, b) 14 Dec 2015.

In addition, the obtained results from mining rockbursts were compared with ones received from the seismic load i.e. El Centro excitation (Table 1). The El Centro excitation is considered as extreme, destructive and its record lasts 53.74 seconds. The ground acceleration during El Centro earthquake is $3.44 \mathrm{~m} / \mathrm{s}^{2}$, what constitutes a magnitude 6.9 on the Richter scale. The numerical model of the soil-steel bridge was loaded in two directions „X” and „Y”, i.e. perpendicular and parallel to the bridge, respectively (Fig. 3) with loads caused by the rockburst and El Centro excitations.

Table 1. Maximum values in shell of soil-steel bridge from mining rockbursts and El Centro excitation.

\begin{tabular}{|c|c|c|c|c|}
\hline \multirow{2}{*}{ Value: } & \multicolumn{2}{|c|}{ Mining rockbursts from: } & \multicolumn{2}{c|}{ El Centro excitation } \\
\cline { 2 - 5 } & $\mathbf{1 2}$ Dec 2015 & 14 Dec 2015 & \multicolumn{2}{c|}{} \\
\cline { 2 - 5 } & \multicolumn{3}{|c|}{ Direction of applied excitations: } \\
\cline { 2 - 5 } & "X" and "Y" & "X" and "Y" & "X" & "Y" \\
\hline Displacements (m) & 0.16 & 0.14 & 0.21 & 0.21 \\
\hline Stresses (MPa) & -58.4 & -51.5 & -91.9 & -89.4 \\
\hline Axial forces (kN/m) & -7006.7 & -6179.64 & -8520.36 & -8758.95 \\
\hline $\begin{array}{c}\text { Bending moments } \\
(\mathrm{kNm} / \mathrm{m})\end{array}$ & 45.16 & 39.55 & 67.03 & 64.36 \\
\hline
\end{tabular}

On the basis of mining rockbursts record and duration, in particular, with a short intense phase, it can be concluded that the rockbursts are a little harmful to the building structures. However, in extreme cases, they can damage a structure. After the Time History analysis, it 
was found that the maximum values were reached in the shell from the mining rockburst on 12 Dec 2015 (Table 1).

The maximum displacement was $0.16 \mathrm{~m}$ (Fig. 5a), while in case of the 14 Dec 2015 rockburst (Table 1) the bridge shell displacement was smaller and equalled $0.14 \mathrm{~m}$. It represents $12.5 \%$ difference in displacements as a result of using both rockbursts. Maximum displacements occurred in the crown of shell structure. Similar differences were achieved in case of stresses, where the maximum values were $-58.4 \mathrm{MPa}$ (Fig. $5 \mathrm{~b}$ ) and $-51.5 \mathrm{MPa}$ from the 12 Dec 2015 and 14 Dec 2015 rockbursts, respectively. It should be noted that the stresses were compressive. The difference between stresses from both rockbursts was $11.8 \%$. The maximum values of stresses were obtained near the shell foundation.

a)

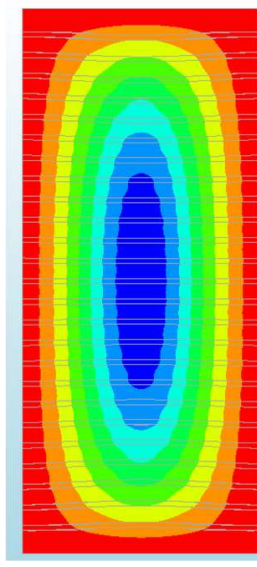

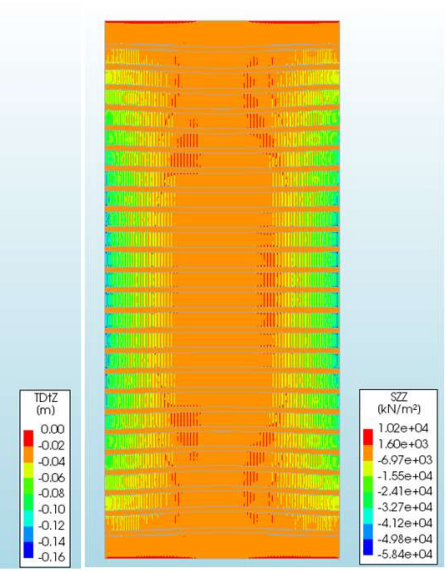

b)

Fig. 5. Maximum values of: a) displacements, b) stresses for 12 Dec 2015 (X - direction).

Analysing the bending moments, the difference in the use of both mining rockbursts was at the level of $12 \%$. The maximum value was $45.16 \mathrm{kNm} / \mathrm{m}$ (Fig. 6b) during rockburst from 12 Dec 2015, and in the other case of excitation, the bending moment was $39.55 \mathrm{kNm} / \mathrm{m}$. Maximum values of bending moments were observed in the middle part of a shell near the foundation - as in the case of stresses.

a)

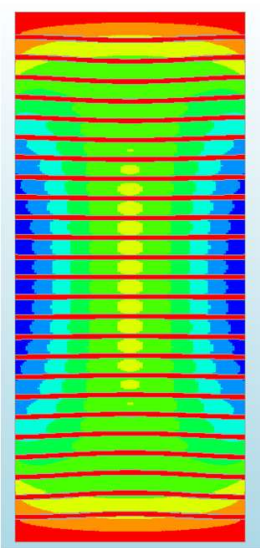

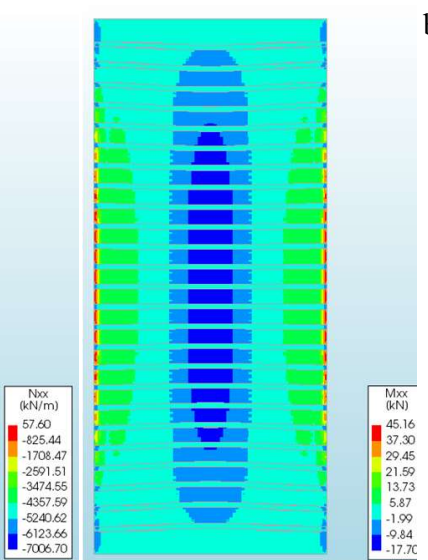

b)

Fig. 6. Maximum values of: a) axial forces, b) bending moments for 12 Dec 2015 (X - direction). 
The same situation was observed in the axial forces, where the difference in both mining rockbursts was almost $12 \%$. The maximum axial forces were $-7006.7 \mathrm{kN} / \mathrm{m}$ and $-6179.64 \mathrm{kN} / \mathrm{m}$ for the $12 \mathrm{Dec} 2015$ (Fig 6a) and 14 Dec 2015 tremors. Maximum axial forces were observed also near shell foundations with the tendency of shifting towards the shell crown. They were also compressive. It should be also underlined that the obtained values of external forces in a soil-steel bridge are the same in both directions of the applied load (,X” and ,Y").

In order to assess the impact of mining rockburst on a soil-steel bridge, it was decided to compare the results with the ones obtained from El Centro earthquake. The bending moment in a steel shell from El Centro earthquake amounted to $67.03 \mathrm{kNm} / \mathrm{m}$. The difference between maximum bending moments caused by seismic excitation and mining tremor was $32.6 \%$ (Table 1). However, in the case of axial forces, less significant differences $(21.6 \%)$ of maximum values caused by rockbursts and El Centro earthquake were observed. The maximum value caused by El Centro excitation was $8520.26 \mathrm{kN} / \mathrm{m}$.

The maximum shell displacements due to El Centro earthquake was $0.21 \mathrm{~m}$ and it was $31.25 \%$ higher, in comparison with maximum displacements obtained from a mining rockburst. In case of a smaller mining tremor (14 Dec 2015), the difference in displacements reached 50\% compared to El Centro excitation. The maximum displacements during El Centro earthquake occurred near the steel shell crown as it was in case of mining rockburst. In case of stresses caused by El Centro earthquake, the maximum value reached $-91.9 \mathrm{MPa}$ and it was observed near steel shell fixing at the foundation. It was higher by $57.4 \%$ than maximum stresses in a shell caused by mining rockburst. In case of the analysis of El Centro earthquake impact, it was observed that the differences in obtained values in both directions were small (did not exceed 3\%). The highest values were reached on the „X” direction (Table 1).

Additional analysis of acceleration and vibration velocity was conducted. It is worth notice that higher shell acceleration was observed for a bridge model of 12 Dec 2015 mining rockburst (Table 2). The acceleration in this case reached $5.39 \mathrm{~m} / \mathrm{s}^{2}$ (Fig. 7a). The other tremor caused the acceleration lower by $45 \%$ and reached $2.95 \mathrm{~m} / \mathrm{s}^{2}$. The highest acceleration of bridge shell was observed at El Centro excitation and it was $23.5 \mathrm{~m} / \mathrm{s}^{2}$.

Table 2. Maximum values of acceleration and vibration velocity in steel shell bridge from mining rockbursts and El Centro excitation.

\begin{tabular}{|c|c|c|c|}
\hline \multirow{2}{*}{ Value: } & \multicolumn{2}{|c|}{ Mining rockbursts from: } & \multirow{2}{*}{$\begin{array}{c}\text { El Centro } \\
\text { excitation }\end{array}$} \\
\cline { 2 - 3 } & $\mathbf{1 2}$ Dec 2015 & 14 Dec 2015 & \\
\hline $\begin{array}{c}\text { Acceleration } \\
\left(\mathrm{m} / \mathrm{s}^{2}\right)\end{array}$ & 5.39 & 2.95 & 23.5 \\
\hline $\begin{array}{c}\text { Vibration velocity } \\
(\mathrm{m} / \mathrm{s})\end{array}$ & 0.0777 & 0.0426 & 0.34 \\
\hline
\end{tabular}

A similar tendency was noticed in case of vibration velocity of a bridge shell. The higher vibration velocity was observed for the 12 Dec 2015 mining rockburst and it was $0.0777 \mathrm{~m} / \mathrm{s}$ (Fig. 7b). In the second case of tremor (14 Dec 2015), the vibration velocity was $0.0426 \mathrm{~m} / \mathrm{s}$ which is $54.8 \%$ of the value caused by the first tremor. The highest vibration velocity was observed for El Centro earthquake and it was $0.34 \mathrm{~m} / \mathrm{s}$. The maximum acceptable acceleration is not always clearly specified, e.g. in the code [11] all live loads affecting the structure should be multiplied by a given factor. The value of the factor varies from 0.8 to 1.25. The code [11] gives values of soil acceleration occurring in Canada. Their values range from 0 to $0.32 \mathrm{~m} / \mathrm{s}^{2}$. In case of used records of mining rockbursts, the highest value of ground acceleration reached $0.8 \mathrm{~m} / \mathrm{s}^{2}$ during 12 Dec 2015 rockburst, while for the second tremor it 
was lower by $45.3 \%$ and reached $0.438 \mathrm{~m} / \mathrm{s}^{2}$. The values were higher than the ones included in code [11] and exceeded the value of $0.32 \mathrm{~m} / \mathrm{s}^{2}$.

a)

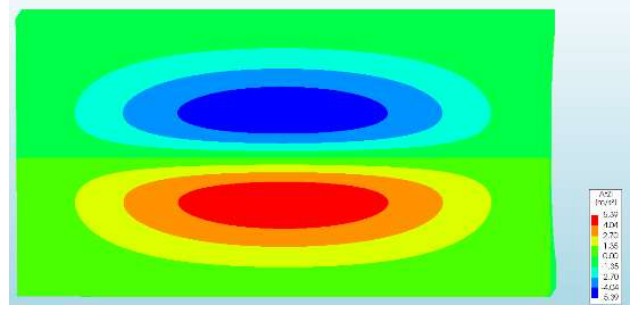

b)

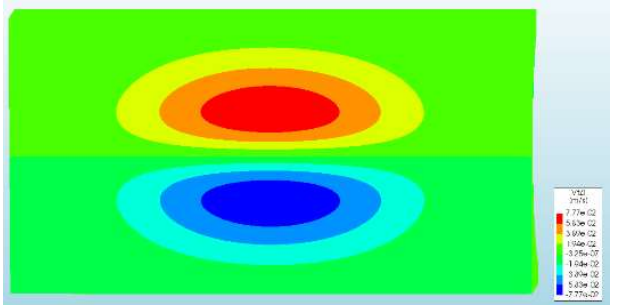

Fig. 7. Maximum values of: a) acceleration and b) vibration velocity from the mining rockburst from 12 Dec 2015 (top view).

An important aspect of the assessment of the impact of seismic and paraseismic loads on soil-steel bridges is the behaviour of the backfill. Analysing the behaviour of soil (backfill) around steel shell, it was noticed that maximum stresses occur near 1/4 of the arch height, near the foundation (Fig. 8a). The maximum stress in backfill were $-1.139 \mathrm{MPa}$ and were obtained from the 12 Dec 2015 mining rockburst. In the second case of a tremor the maximum stress was lower by $12.1 \%$. However, in case of El Centro earthquake, the maximum stress in backfill reached $-1.565 \mathrm{MPa}$ and it was higher by $37.4 \%$ than the ones obtained from mining rockbursts. As in case of mining tremors, the maximum stresses were observed near shell foundation. The highest backfill displacements caused by a mining rockburst reached $0.16 \mathrm{~m}$ and occurred in a steel shell crown (Fig. 8b). In case of the El Centro earthquake, the maximum backfill displacements were located in a shell crown and had the value of $0.21 \mathrm{~m}$. It should be pointed that maximum backfill displacements are the same as shell displacements. It results from take adequate parameters of steel shell and soil interaction.

a)

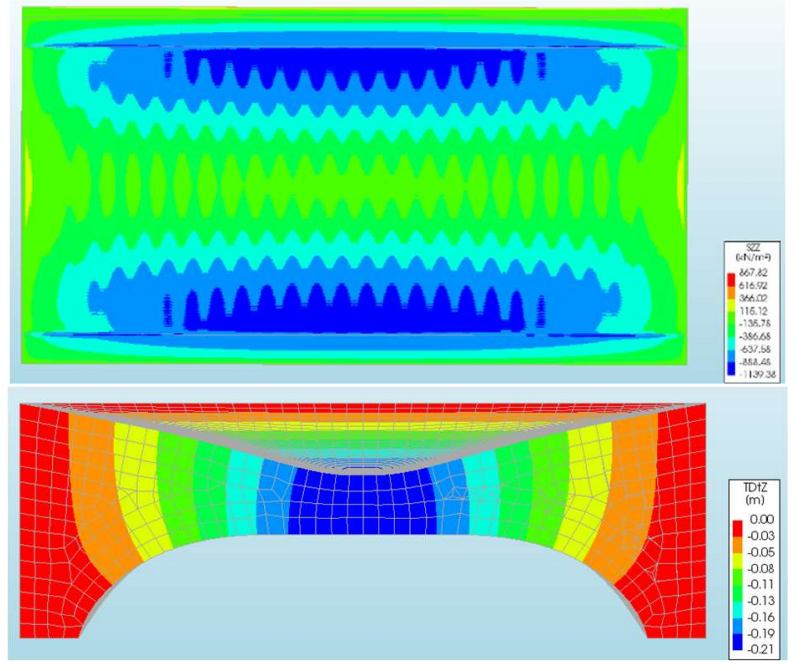

Fig. 8. Maximum values of: a) stresses, b) displacements in backfill of soil-steel bridge from mining rockburst from 12 Dec 2015 (X - direction).

\section{Conclusions}


Based on the conducted analysis of soil-steel bridge with the use of Time History analysis and finite element method with the application of a numerical program DIANA, the following conclusions can be drawn:

- The duration of the mining rockburst is important for obtained values of internal forces in the analysed soil-steel bridge shell. The longer the rockburst, the higher the values of internal forces. In the analysis, the difference of internal forces in a steel shell between two applied mining rockbursts equalled about $12 \%$. This conclusion is consistent with the paper by Zembaty [17].

- The direction of seismic load application (perpendicular or parallel to the bridge structure) is not relevant for non-destructive and low intensity loads. Differences were observed in the case of much stronger El Centro extreme load, for which higher values of internal forces were obtained.

- The highest values of displacements from mining rockbursts were obtained in the crown of shell structure and amounted to $0.16 \mathrm{~m}$ which is $68.75 \%$ of displacement value from El Centro excitation amounting $0.21 \mathrm{~m}$,

- Maximum values of bending moments, axial forces and stresses were located in the middle part of shell, near the soil-steel bridge foundation. It should be noted that the stresses and axial forces had a compressive character. Applied paraseismic and seismic loads did not exceed steel yield strength which is $235 \mathrm{MPa}$ for the analysed numerical model.

- Maximum values of bending moments and axial forces obtained as a result of mining rockbursts are respectively $67.4 \%$ and $78.4 \%$, compared to the case of El Centro seismic load.

- Ground acceleration affects the obtained values of internal forces and displacements in the steel shell. The greater ground acceleration, the higher values of internal forces and displacements.

- Acceleration and vibration velocity of bridge shell excited by mining rockburst are significantly lower (about $77 \%$ both for acceleration and the vibration velocity) than when using El Centro earthquake excitations.

- After the analysis of a soil-steel bridge seismic response it can be stated that it is resistant to the mining rockburst selected in this research. It should be pointed out that it is one of the strongest rockburts recorded in Poland. The level of response suggests that there is a danger of loosening and displacement of backfill around the shell which can reduce the durability of these bridges. To clarify this issue further research is necessary.

\section{References}

1. L. Janusz, A. Madaj, Engineering Structures from Corrugated Plate: Design and Construction, Transport and Communication Publishers, Warsaw, Poland (2009)

2. Cz. Machelski, Modeling of Soil-Shell Bridge Structures, The Lower Silesian Education Publishers, Wroclaw, Poland (2008)

3. D. Beben, Backfill corrosivity around corrugated steel plate culverts, J Perform. Constr. Facil., 29 (2015)

4. Z. Zembaty, S. Kokot, F. Bozzoni, L. Scandella, C.G. Lai, P. Bobra, A system to mitigate deep mine tremor effects in the design of civil infrastructure, Int. J. Rock Mech. Min. Scien., 74 (2015)

5. Z. Zembaty, S. Kokot, Adaptation of seismic civil engineering standards to the design of structures under the excitation from mine tremors, Mining Overview, 6 (2014) 
6. Z. Zembaty, How to model rockburst seismic loads for civil engineering purposes?, Bull. Earthquake Eng., 9, 5 (2011)

7. P.A. Bońkowski, Z. Zembaty, M.Y. Minch, Time history response analysis of slender tower under translational-rocking seismic excitations, Eng. Struct., 155 (2018)

8. Y. Sawamura, K. Kishida, M. Kimura, Experimental study on seismic resistance of a two-hinge precast arch culvert using strong earthquake response simulator, The $15^{\text {th }}$ Asian Regional Conference on Soil Mechanics and Geotechnical Engineering (2015)

9. O. Abuhajtar, H. El Naggar, T. Newson, Seismic soil-culvert interaction, Can. Geotech. J., 52 (2015)

10. A. Maghgoub, H. El Naggar, Assessment of seismic provisions of the CHBDC for CSP culverts, GeoOttawa 2017 (2017)

11. CHBDC, Canadian Highway Bridge Design Code. CAN/CSA-S6-06, Canadian Standards Association International (2006)

12. T. Maleska, P. Bońkowski, D. Beben, Z. Zembaty, Transverse and longitudinal seismic effects on soil-steel bridges, Conference: Eight European Workshop on the Seismic Behaviour of Irregular and Complex Structures (2017)

13. C.A. Davis, J.P. Bardet, Responses of buried corrugated metal pipes to earthquakes, J. Geotech. Geoenv. Eng., 126 (2000)

14. DIANA FEA, Available online from URL: www.dianadea.com/ (2017)

15. D. Beben, J.A. Stryczek, Finite element analysis of soil-steel arch bridge, Maintenance, Monitoring, Safety, Risk and Resilience of Bridges and Bridge Networks, 1378-1385 (2016)

16. G. Pittino, J. Gosler, Structural plate steel underpasses during backfilling - how to minimize the bending moment, 4th International Conference FLAC Symposium on Numerical Modelling in Geomechanic (2006)

17. Z. Zembaty, Rockburst induced ground motion - a comparative study, Soil Dyn. Earthquake Eng., 24 (2004) 